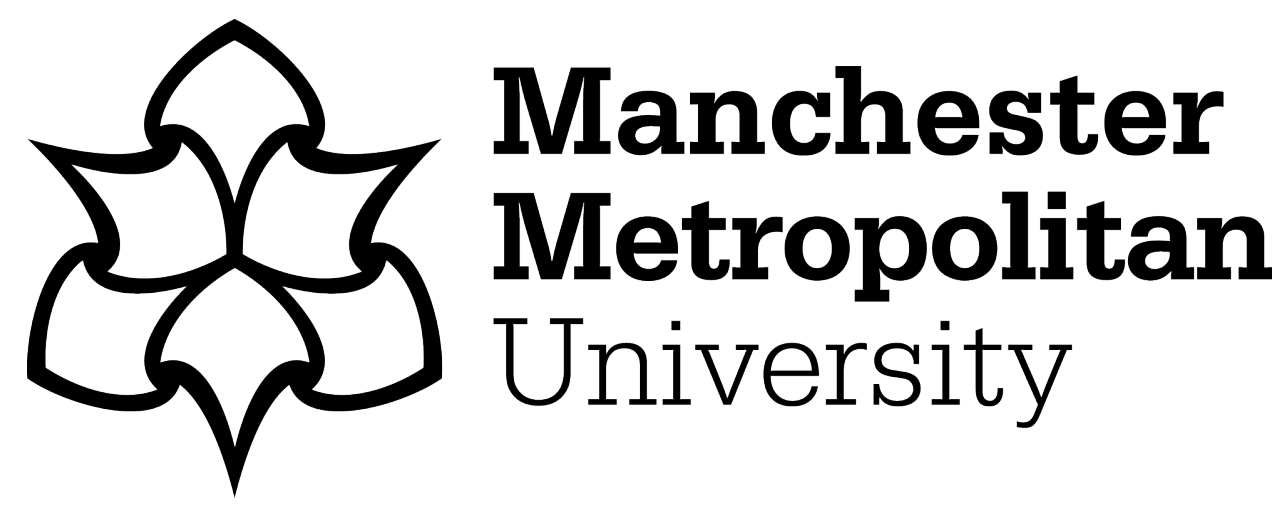

Kharuhayothin, T and Kerrane, B ORCID logoORCID: https://orcid.org/00000003-2114-5965 (2018) Learning from the past? An exploratory study of familial food socialization processes using the lens of emotional reflexivity. European Journal of Marketing, 52 (12). pp. 2312-2333. ISSN 0309-0566

Downloaded from: https://e-space.mmu.ac.uk/624175/

Version: Accepted Version

Publisher: Emerald

DOI: https://doi.org/10.1108/EJM-10-2017-0694

Please cite the published version 


\section{Lancaster University Management School: Author Accepted Manuscript}

This is an 'accepted manuscript' as required by HEFCE's Open Access policy for REF2021.

Please cite this paper as:

Tanyatip Kharuhayothin and Ben Kerrane (forthcoming), Learning from the past? An exploratory study of familial food socialization processes using the lens of emotional reflexivity

ACCEPTED FOR PUBLICATION | May 23, 2018

ORCID NUMBER: 0000-0003-2114-5965

DOI: 10.1108/EJM-10-2017-0694

Ben Kerrane

Senior Lecturer in Marketing

Lancaster University Management School

Lancaster, LA1 4YX

\section{f日圖 in}

TRIPLE-ACCREDITED, WORLD-RANKED

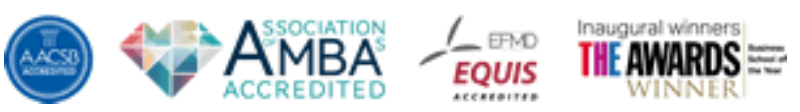




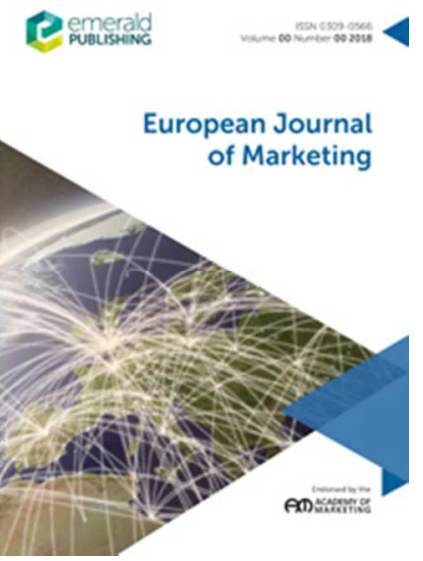

\section{Learning from the past? An exploratory study of familial food socialization processes using the lens of emotional reflexivity}

\begin{tabular}{|r|l|}
\hline Journal: & European Journal of Marketing \\
\hline Manuscript ID & EJM-10-2017-0694.R1 \\
\hline Manuscript Type: & Original Article \\
\hline Keywords: & $\begin{array}{l}\text { Family, Food Socialization, Intergenerational Influence, Emotional } \\
\text { Reflexivity, Parents, Children }\end{array}$ \\
\hline
\end{tabular}

\section{SCHOLARONE ${ }^{\mathrm{m}}$}




\title{
Learning from the past? An exploratory study of familial food socialization processes using the lens of emotional reflexivity
}

\begin{abstract}
Purpose: This paper aims to explore the parental role in children's food socialization. More specifically, it explores how the legacy of the past (i.e. experiences from the participant's own childhood) work to inform how they, in turn, socialize their own children within the context of food, drawing on theories of consumer socialization, intergenerational influence and emotional reflexivity.

Design/methodology/approach: To seek further understanding of how temporal elements of intergenerational influence persist (through the lens of emotional reflexivity), the authors collected qualitative, interpretative data from thirty parents from the UK using a combination of existential-phenomenological interviews, photoelicitation techniques and accompanied grocery shopping trips (observational interviews).

Findings: Through intergenerational reflexivity, parents are found to make a conscious effort to either 'sustain' or 'disregard' particular food practices learnt from the previous generation with their children (abandoning or mimicking the behaviours of their own parents within the context of food socialization). The factors contributing to the disregarding of food behaviours (new influencer, self-learning and resistance to parental power) emerge. A continuum of parents is identified, ranging from the 'traditionalist' to 'improver' and the 'revisionist'.

Originality/value: By adopting a unique approach in exploring the dynamic of intergenerational influence through the lens of emotional reflexivity, this study highlights the importance of the parental role in socializing children about food; and how intergenerational reflexivity helps inform parental food socialization practices. The intergenerational reflexivity of parents is, thus, deemed to be crucial in the socialization process.
\end{abstract}

Keywords Family, Food Socialization, Intergenerational Influence, Emotional Reflexivity, Parents, Children

Paper type Research paper 


\section{Introduction}

Given that 'the family' is considered to be the primary consumption and socialization unit (O’Malley and Prothero, 2006) with early familial socialization influences shaping consumption patterns throughout our lifetime (Marshall and O'Donohoe, 2010; Kerrane et al., 2014), understanding how the family influences children's socialization into particular patterns of consumption remains a significant topic of interest. Several studies highlight that parents play a major role in developing children's eating behaviours because parents are the most powerful socialization agents for young children, especially surrounding food practices (Dotson and Hyatt, 2005; Marshall et al., 2007; Peters et al., 2014). As food consumption is considered to be the very first consumer skill that parents develop in their children (Hughner and Maher, 2006), understanding how parents shape children's food consumption is an important topic that needs further exploration (Marshall et al., 2007; Grier and Moore, 2012; Russell and Worsley, 2013).

This paper draws on the concept of emotional reflexivity (Holmes, 2010; 2015) to forge a deeper understanding of how parents shape the food socialization of their children within the family setting. Emotional reflexivity "refers to the intersubjective interpretation of one's own and others' emotions and how they are enacted" (Holmes, 2015, p. 61) and offers useful guidelines to parents to either continue or discontinue their own parents' food practices with their children (through intergenerational influence). Emotional reflexivity, thus, allows individuals to navigate a "new path", representing a useful theoretical lens through which to explore how the actions and legacy of the previous generation work to inform current food socialization processes, as played out by parents.

Although intergenerational influence and the transfer of consumption practices from one generation to the next have been explored within the context of consumer socialization, signifying its importance for the consumer market, (Carlson et al., 1994; Moore et al., 2001; Epp and Price, 2008), calls have been made for further research which explores how such intergenerational influence is conveyed (Moore et al., 2002). Drawing on the recent work of Moore et al. (2017), who highlight the relative scarcity of studies which explore how temporal elements ('persistence vs. change') of intergenerational influence shape food consumption decisions, we seek to answer the 
following research question: “are today's parents drawing from what they learned as children from their parents" (Moore et al., 2017, p. 846) within their own food socialization practices?

\section{Food socialization and parents}

Introduced by Ward (1974), consumer socialization represents processes by which children acquire skills, knowledge, and attitudes relevant to their functioning as consumers in the marketplace. Food socialization specifically refers to how consumers learn to consume food and its cultural role regarding food well-being (Block et al., 2011), with family food socialization "the process by which parents' preferences, beliefs, and attitudes toward food shape their children's food-related beliefs, attitudes, knowledge, preferences, and consumption, which in turn influence eating behaviours" (Nicklas et al., 2009, p. 227). Studies highlight that food socialization begins during our childhood years, fostering the formation of consumption practices which endure throughout our lifetime (Ward, 1974; Moschis and Churchill, 1978; Birch and Fisher, 1998; Ekström, 2006; Block et al., 2011).

Although children might obtain food consumption skills from several socialization agents (i.e. family, peers, school, and mass media), parents are the most powerful socialization agent and play the most significant role regarding the formation of children's food consumption skills (Moschis and Churchill, 1978; Moschis and Moore, 1979; Dotson and Hyatt, 2005; Hughner and Maher, 2006). Parents assume the role of teacher when interacting with their offspring (Lawlor and Prothero, 2011) and act as the policymakers of the home (Hughner and Maher, 2006) and gatekeepers of their children's purchasing (White and Davis, 2006); controlling and making specific food available to them (Hughner and Maher, 2006; Marshall et al., 2007).

Attitudes of parents regarding food consumption subtly influence children's food exposure and their diet preferences through parental food practices and role modelling behaviours (Wardle, 1995). Parents' attitudes and practices affect not only the food available in the household, but also the food portions, timing, and emotions associated with the social context of mealtime experiences (Birch et al., 2001). As such, parents are likely to play a crucial role in forming food consumption practices, 
as well as food preferences, of their children (Hughner and Maher, 2006; Ayadi and Bree, 2010; Judd et al., 2014). However, studies regarding parental influence on children's knowledge and attitudes relating to food consumption remain somewhat limited (Marshall et al., 2007; Grier and Moore, 2012; Pedersen et al., 2012; Russell and Worsley, 2013).

\section{Intergenerational influence and food socialization}

Intergenerational influence can be primarily defined as the information, beliefs, and resources that are transmitted from one generation to another within the family unit (Moore et al., 2001, 2002). Embedded within consumer socialization, intergenerational influence/transfer is an interesting and important topic to study (Carlson et al., 1994; Moore et al., 2001; Epp and Price, 2008), with socialization theories suggesting that familial consumption attitudes and beliefs endure and stay with children as they grow older (Birch and Fisher, 1998; Birch et al., 2007; Marshall and O'Donohoe, 2010). The effects of intergenerational influence tend to erode, however, after the first few years one leaves home when faced with new consumption settings, posing an interesting question in the dynamic of intergenerational influence when ones move away from our first family setting (Moore et al., 2002, 2017).

Whilst previous studies have explored intergenerational influence in the context of consumption, including studies of the intergenerational transfer of brand preferences (Moore et al., 2002), shopping habits of mothers/daughters (Grønhøj and Thøgersen, 2009), and transfers of pro-environmental behaviors (Minahan and Huddleston, 2010), further exploration of intergenerational influence within consumer research has been called for as several questions (such as are today's parents drawing from what they learned as children from their parents in their own familial socialization behaviours?) remain unaddressed (Moore et al., 2002, 2017).

It is proposed that the forces that shape familial food socialization practices can be contemporaneous whilst simultaneously having historical links (Judd et al., 2014). That is, current consumption practices and behaviours can be drawn from the practices employed by previous generations. Recognising the importance of the family's legacy within early family experiences, studies are needed that explore the intergenerational influence on food socialization practices (Judd et al., 2014; Kerrane 
et al., 2014). Within the discipline of nutrition, the transfer of food taste and food preferences from parents to children has been examined (see, for example, Kral and Rauh, 2010), signifying that the transfer of food preferences is valuable and considered as part of the socialization process. However, relatively little consumer research has given attention to exploring intergenerational influence in the context of food consumption, with the work of Gram, Hogg, Blichfeldt, and MacLaran (2015) and Moore et al. (2017) notable exceptions. In their recent work exploring the links between parental role and childhood obesity, Moore et al. (2017) highlight dynamic aspects of intergenerational transfer as representing promising opportunities for future research. They discuss temporal elements (persistence or change in familial food consumption) within the dynamic of intergenerational influence as an important future research area that can help expand our understanding of intergenerational influence processes (Moore et al., 2017).

Within consumer research, knowledge of intergenerational influence often focuses on whether the intergenerational influences exists (Moore, 2010); but studies that explore whether intergenerational influence endures throughout adulthood, especially the temporal dimensions of intergenerational influence (i.e. whether parents draw from the practices they learned when they were children), are limited and represent an essential direction for further study (Moore et al., 2001, 2017).

\section{Intergenerational/emotional reflexivity}

Theories of reflexivity relate to the process in which one acts or alters one's practices in response to existing knowledge of the situation one finds himself/herself in (Holmes, 2010, 2015). Emotional reflexivity is suggested to evolve from traditional reflexivity in that self-reflection and feelings are thought to be encapsulated in a reflexive process (Holmes, 2010, 2015), constituted in interactive relations with others. As Holmes (2010) argues, reflection and emotion are at the heart of the reflexive process, which governs how an individual thinks, feels and performs (as influenced, in our context, by the generation before). Emotion entangles the ways we monitor our behaviours and informs how we make life choices - and as such, cannot be detached from the process of reflexivity (Burkitt, 2012). 
Tradition impacts the way people make sense of their lives (Adkins, 2000; Gross, 2005). Previously, theories of reflexivity have predominantly focused on the ways people monitor and make changes to their lives using their knowledge about new circumstances, in which people often deal with unknown circumstances through which they are not able to rely on past routines, customs and traditions (Giddens, 1990). Theories of reflexivity, therefore, focus primarily on de-traditionalisation and risk as a result of the difficulty in making decisions within an uncertain modern world (Beck, 1992; Giddens, 1990, 1992). However, traditional reflexivity theorists have largely ignored the roles other people play in shaping (one's own) reflexivity (Burkitt, 2012); and have detached the concept of self-reflection from reflexivity, particularly when one comes to understand one's self, the meaning of one's actions and one's biographical narrative. Traditional theories of reflexivity are thus too 'individualistic' and 'rationalistic' as they set aside emotion from the process of reflexivity (Burkitt, 2012, p.464). Holmes $(2010,2015)$ stresses that emotional reflexivity is vital in the process of social reproduction, yet little direct research attention has been paid to emotional reflexivity. Similarly, Mason (2004, p. 167) suggests that studies of how individuals "reflect in distinctive ways upon their experiences ... with others, as well as their sense of self" through emotional reflexivity are missing from the existing literature.

In relation to parenting, emotional reflexivity has been used (implicitly) to explain how parents draw on "emotions to navigate their path, especially when facing new situations or ways of living" (Holmes, 2015, p. 61). Reflection on the past (i.e. the roles/actions of their own parents) infuse actions and behaviours of the present. Support exists, for example, to suggest that the parental style an individual adopts is likely shaped and influenced by the role played by his/her own parent(s) (see, for example, Carlson et al., 1994). A recent study of new fatherhood, as one illustration of this, shows how men actively reject the outdated breadwinner model of fatherhood enacted by their own fathers (described as emotionally stoic and detached) in their pursuit of the more emotionally present, 'involved father' role (Bettany et al., 2014). Emotion is thus entangled in how we behave and must be studied from within consciousness (Denzin, 1984). Reflecting on thoughts and feelings can lead to changes in behaviours, such as the propensity for parents to reflect on how their own parents parented - using this as a temporal and emotional barometer to inform how they would like to parent their offspring. 
Our understanding of the parental role as the most influential socialization agent for young children in forming consumption practices (e.g. Moschis and Churchill, 1978; Dotson and Hyatt, 2005; Hughner and Maher, 2006), combined with the knowledge that intergenerational influence exists and permeates life decisions (Moore et al., 2002), provides us with the initial point to explore how parents teach their children about food through the impact of intergenerational influence (i.e. whether food patterns parents learned as children from their parents endure, and are subsequently enacted or disregarded by parents with their own children).

We highlight the following research gaps; first, there is a lack of understanding of how parents form/shape the food practices of their children (Marshall et al., 2007; Grier and Moore, 2012; Russell and Worsley, 2013), especially in terms of how parents inform children's healthy eating behaviours (Ayadi and Bree, 2010; Pedersen et al., 2012); second, there is a need to study temporal dimensions within the process of intergenerational influence in terms of understanding how parents draw from their past learning experiences about food in connection to their current consumer socialization of their own children (Moore et al., 2017); and, finally, there is a lack of studies that directly utilise emotional reflexivity to help understand food choice and preferences (Holmes, 2010, 2015; Burkitt, 2012). This study, thus, seeks to further explore the parental role in shaping the process of children's food socialization, exploring the legacy of intergenerational influence through the lens of emotional reflexivity.

\section{Methodology}

We adopt a qualitative, interpretative approach to data collection and draw on data collected through existential phenomenological interviews, photo elicitation techniques/a (food) diary keeping task as well as accompanied grocery-shopping trips with parents to understand their food socialization behaviours and motivations. Such an approach to data collection aligns with Moore et al.'s (2002) proposition that studies of intergenerational influence are best explored through qualitative methodologies, with Holmes (2015) advocating the use of interviewing to obtain greater insight into emotional reflexivity.

Thirty parents who self-identified as the primary food preparer for their family, 
following Judd et al. (2014), took part in this study (see Table 1). Consistent with other studies of food socialization the majority of our participants are female/mothers $(n=22)$, although a relatively small number of men/fathers opted in $(n=8)$. We feel this reflects the growing presence of men in family life, food preparation and grocery shopping (see, for example, Cabrera et al., 2000; Gram, 2015). It should be noted, however, that we refer to 'parent-child' relationships within our findings/discussion section (rather than mother-child/father-child in particular) despite the majority of our participants being mothers. Identifying gender differences between mothers/fathers is not the central focus of our study, which instead explores food socialization behaviours at a general level. However, we recognise that others (see Del Bucchia and Penaloza, 2016) have identified differences between mothers/fathers in the context of feeding the family, a theme that we return to within our directions for future research section.

Thus, parents (mothers or fathers) of younger children (less than 12 years old) were purposively recruited from the North West region of the United Kingdom. Parents of younger children were specifically recruited because parents exert the greatest influence on children until adolescence (where peers start to become more influential) (Moore and Moschis, 1980). At this age (up to 12 years old) influences on child consumption are largely contained to the family unit (John, 1999), with children likely to be closely supervised and food consumption dictated by parents (Birch et al., 2007). The participants were recruited through social media, nurseries and primary schools (places where young children were present). As parents are considered the gatekeepers of their child's consumption, they can speak from their child's point of view through their experiences of being closest to them (Marshall et al., 2007) (although again, we recognise the need for future research which actively seeks the voice of children in studies of food consumption). 
Table 1: Participant Profile Table

\begin{tabular}{|c|c|c|c|c|c|c|}
\hline $\begin{array}{l}\text { Name } \\
\text { pseudonym }\end{array}$ & Gender & $\begin{array}{l}\text { Number of } \\
\text { children }\end{array}$ & Age of children & Occupation & Marital status & $\begin{array}{l}\text { Emotions associated with } \\
\text { intergenerational reflexivity }\end{array}$ \\
\hline Abigail & Female & 3 & $10,12, \& 21$ years & Housewife & Married & Positive \\
\hline Amy & Female & 1 & 3 years & Administrator & Married & Positive/Negative \\
\hline Claudia & Female & 1 & 7 months & Lecturer & Married & Positive/Negative \\
\hline Daisy & Female & 1 & 1.5 years & High school teacher & Married & Positive/Negative \\
\hline Ellie & Female & 2 & 5 years - twins & Sales Assistant & Single & Positive/Negative \\
\hline Fran & Female & 2 & $9 \& 6$ years & Lecturer & Married & Positive/Negative \\
\hline Fiona & Female & 2 & $6 \& 8$ years & Housewife & Married & Positive \\
\hline George & Male & 1 & 20 months & Lecturer & Living with Partner & Positive \\
\hline Ian & Male & 3 & $12,16, \& 21$ years & Lecturer & Divorced & Positive \\
\hline Isabella & Female & 2 & $4 \& 7$ years & Musician & Married & Positive \\
\hline Jane & Female & 2 & $9 \& 15$ years & Sabbatical & Married & Positive/Negative \\
\hline Jennifer & Female & 2 & $1 \& 3$ years & Housewife & Married & Positive/Negative \\
\hline Jonathan & Male & 2 & $5 \& 7$ years & Student & Married & Positive/Negative \\
\hline Joy & Female & 2 & $7 \& 11$ years & NHS Officer & Married & Positive/Negative \\
\hline Kate & Female & 1 & 12 years & Counsellor/Therapist & Single & Positive \\
\hline Kayla & Female & 1 & 4 years & HR Advisor & Married & Positive/Negative \\
\hline Mary & Female & 3 & $7,12, \& 15$ years & Lecturer & Married & Positive/Negative \\
\hline Max & Male & 2 & $2 \& 6$ years & Lecturer & Married & Positive \\
\hline Natalia & Female & 2 & $4 \& 6$ years & Sales Assistant & Living with Partner & Positive/Negative \\
\hline Natasha & Female & 2 & $9 \& 10$ years & Student & Married & Negative \\
\hline Nick & Male & 1 & 2 years & Economist & Married & Positive/Negative \\
\hline Naomi & Female & 1 & 5 years & Housewife & Married & Positive \\
\hline Olivia & Female & 2 & $2 \& 9$ years & Housewife & Married & Positive/Negative \\
\hline Pete & Male & 1 & 4 years & Student & Married & Positive/Negative \\
\hline Rachel & Female & 1 & 4 years & Software Professional & Married & Positive \\
\hline Ray & Male & 1 & 4 years & Banker & Married & Positive/Negative \\
\hline Rebecca & Female & 1 & 3.5 years & Artist & Married & Negative \\
\hline Sandra & Female & 2 & $9 \& 11$ years & Cleaner & Married & Positive \\
\hline Tony & Male & 3 & $12,21, \& 26$ years & Local Government Worker & Living with Partner & Negative \\
\hline Wendy & Female & 1 & 2 years & Housewife & Married & Positive/Negative \\
\hline
\end{tabular}


Data collection comprised two main stages. The first stage consisted of an existential-phenomenological interview, best used when participants possess rich detail of a given topic (Thompson et al., 1990), capable of capturing their emotions, knowledge, and thoughts (Belk et al., 2013). The interview was conducted alongside a photo-elicitation technique using participant photo diaries which help bring out deeper human emotions than words/interview alone (Harper, 2002). Parents were asked to keep a photo diary (using their smartphones) of the food they prepared for their children, the food inside their kitchen cabinets, and the food inside their refrigerator over a one-week period. Parents were then asked to discuss the photos that they had taken at the beginning of their in-depth interview. Broad, open-ended questions were posed, exploring how parents thought they formed the food practices of their children and whether parents practised any food-related customs/behaviours with their children that they had learned as a child (through the policies of their own parents).

The photo-elicitation interview holds great potential for food research due to its ability to elicit particular information that may be difficult to capture from other methods (Alm and Olsen, 2016). Clark-IbáÑez (2004) suggests that photo-elicitation helps the researcher gain access to the participant's home and life without the researcher physically being present, and, thus, creates a more intimate setting than a typical interview. The photographs from the photo diaries were used to help stimulate discussion during the in-depth interviews, a technique successfully utilised by others in the study of food consumption (Harman and Cappellini, 2014, 2015).

The second stage of data collection involved accompanied grocery-shopping trips, which shed greater light on understanding the first-hand experiences of participants in their natural setting (Belk et al., 2013). The participants were accompanied on one of their grocery-shopping trips after the first in-depth interview had taken place. Sunderland and Denny (2007) suggest that people feel more comfortable expressing their feelings in the appropriate setting (in this case, local supermarkets).

The interviews were audio recorded with the consent of participants, and procedures were taken to ensure the ethical credibility of the research project. Interviews were transcribed verbatim, coded and analysed using Interpretative 
Phenomenological Analysis (IPA), with IPA allowing the researcher to interpret the person's experience in a given phenomenon/context (Palmer et al., 2010). IPA helps to explain the phenomenological stance on how people make sense of their lived experiences (Smith et al., 2009; Braun and Clark, 2013). The food socialization stories we recount emerge from thirty participants, in which the development of emergent themes was completed for each participant before considering that of the next participant (Braun and Clark, 2013). Such a process ensures the idiographic focus of IPA (Smith et al., 2009). The common patterns of distinct emergent themes across each participant were then compared, connected and mapped (Smith et al., 2009) to enhance a greater understanding of the parental role in children's food socialization processes.

\section{Findings}

Strong intergenerational reflexivity regarding previous food practices among parents emerged within the family stories (i.e. participants strongly reflected on the food practices that their parents performed when they were a child (and associated emotions) and carefully considered whether these were appropriate behaviours to enact with their children/their eating habits). Through intergenerational reflexivity, parents drew on emotions, ranging from love, respect and nostalgia, through to resentment, as associated/recalled from past experiences of food socialization as a child (during their primary socialization). Figure 1 depicts the emerging framework that highlights how parents experience intergenerational influence(s) in food consumption, guided by their intergenerational reflexivity. Parents are influenced by their own childhood food consumption experiences, acquiring values or norms in food consumption in the forms of habits that they reproduce or disregard with their children (Knight et al., 2014). While participants tend to follow certain food habits ('sustaining' or 'reproducing patterns of behaviour') as informed by their parents, they also tend to make conscious efforts not to practice other food habits ('disregarding' or 'dismissing patterns of behaviour') that they have learned from their mother/father (with emotion strongly influencing whether such food practices/patterns are retained or abandoned). 
Figure 1: The components of intergenerational reflexivity in familial food consumption

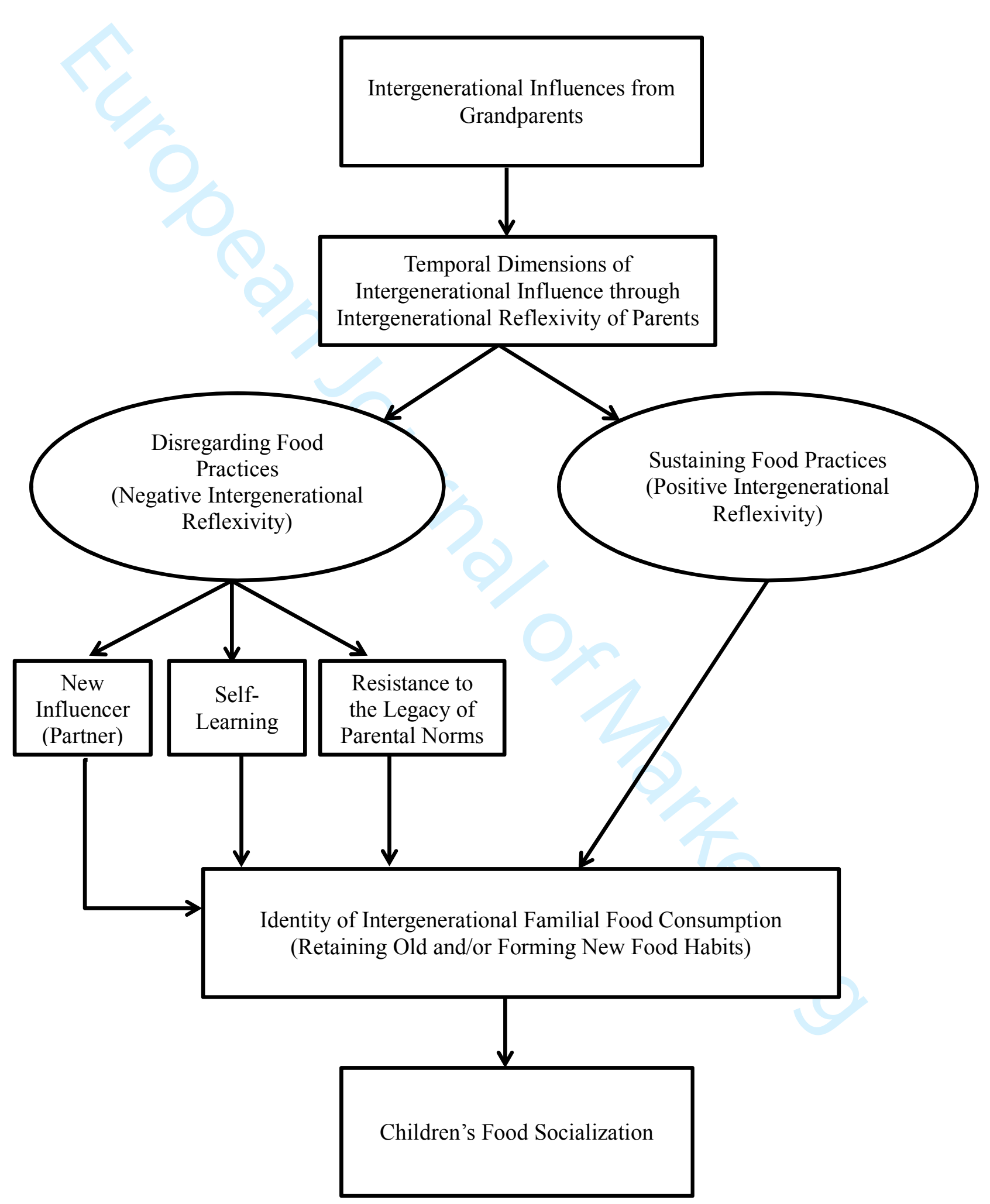




\section{Disregarding food practices}

The food practices that participants recalled from their past (i.e. those performed by their parents when they were a child) worked to inform current food socialization practices with their own family/children. Participant's memories and past experiences as a child often provoked negative reflection which led to a different food socialization style being performed (in comparison with their parents). Our participants spoke with great animosity about some of the actions/food socialization behaviours undertaken by their own parents (e.g. the enforcement of overly strict table manners; the punitive role of cleaning their plates; being forced to eat food they did not like, or food now viewed as being unhealthy), with several participants actively rejecting their parent's food socialization style. Similarly, other factors (e.g. the presence of a new influencer (their spouse) or self-learning) also led to disregarding the food practices of the previous generation.

\section{Resistance to the legacy of parental norms}

Many participants recalled that they did not like being forced by their parents to eat food that they disliked as a child. Participants who recall such experiences (which resonates with Lupton, 1994) do not want to perform the same patterns/food socialization styles with their own children ("Why would I like to be so Victorian, so strict, like them?"). In a study of intergenerational relations, Knight, Connell, and Brannen (2014) propose that the struggling of power between parents' attempts to control the child's consumption, and the child's resistance to that power through refusing to eat food, has a lasting effect from the past to the current intergenerational relationship ("I look back and think my God, no! They forced me to eat that muck? I'll never be like that with my kids ... I can never forgive them for doing that").

The reflections of the past of being forced to eat food they did not like has not only triggered a feeling of dislike, but also reminds participants of having less-power status at that (childhood) time ("It makes me feel so passive; my children are a lot more involved in the food choices I offer them" and "It stirs up feelings of being sick, of feeling sick, and pretty much being force-fed food that made me vomit"). Thus, such relationships create negative feelings associated with intergenerational influence 
in this context of food consumption. Natalia, for example, recalls that her mother was "quite strict" and would make her "sit there to eat everything ... but with these two [children], I don't wanna be like that. I want to make it different". Similarly, Jennifer equally recalls that there were lots of food that she disliked as a child, yet she was forced to clean her plate: "I absolutely hate them for doing that to me". Thus, Jennifer does not force her own children to finish any food that they dislike. Similarly, Fran also shares that when she was growing up meal times were "very formal", commenting that she is much more relaxed with her own children as a consequence:

"Oh God, no, my parents were quite Victorian. ... When I was growing up in the 1970s dinner was very formalised. You know, it was that whole kind of you don't put your elbows on the table, you don't do this, and you don't do that. And the role of children in our society was far more strongly controlled in terms of behaviour whereas I'm oh for God's sake, if you want to put your elbows on the table, you go ahead. I'm much more relaxed".

The examples above demonstrate that emotional reflexivity opens the space to challenge the restrictive table manners and unpleasant food rituals/rules of the past, in which reflexivity goes beyond mere self-reflection. The participants alter their previous practices according to their own reasoning, based on recalled emotions and the emotions of others (i.e. their own children's welfare and emotional wellbeing). Thus, they are taking the conscious choice of not forcing their children to eat what they dislike/to clean their plates even when they hate the taste of the food offered to them ("It was like some kind of prison; eat this, and eat it all, or there would be punishments"). Parents clearly treated certain habits of the previous generation as a past mistakes, derived from the negative feelings associated with intergenerational influence during the reflexive process.

As a final example to this section of our findings, Rebecca's father would allow her to eat "whatever you want in the trolley" during grocery-shopping trips (often sweets, chocolates and fizzy drinks); and he would put sweets in a cupboard underneath the stairs that were freely available to her, using what he labelled a "naughty box". The negative connotation associated with the word "naughty" implies that her father knew that those sweets were bad/were unhealthy for her - and Rebecca now has great feelings of guilt in consuming such unhealthy products as a child. Whereas it could be argued that contemporary parents are more literate in terms of the 
ideal nutritional intake of their children than the previous generation (see Hart et al., 2015), depicting a recent trend towards "healthism" which encourages personal responsibility for health through the rise of a healthy eating agenda (Delaney and McCarthy, 2014), here Rebecca's father openly acknowledges the unhealthy traits of the food in the "naughty" box yet does not restrict her access to them. Rebecca, then, perceives this as a bad, guilty habit - and she is clear that she does not want to emulate such a practice with her own child: "My dad was terrible ... don't do what my dad did".

\section{Self-learning}

Participants who disregard their parent's "negative" food practices/teaching seek new food practices, which are more attractive and rewarding in their parenting role. The significant alterations/disruption in daily consumption routines come from learning that there are other eating habits beyond the norms learned from home as a young child (Moore et al., 2002). Tony, for example, is highly critical of the poor feeding style of his parents - particularly his mother, who he describes as an "appalling cook" - who would frequently offer him "chips and convenience food", fostering a "very poor attitude to food". Tony has made it his priority to enact a 'better' style of parenting with his own children, taking charge of the family's meal preparations and embracing vegetarianism to ensure that his children eat good, nutritious meals:

"My mother ... she just can't cook. She was from an Irish family, and so you boiled potatoes, or you chipped potatoes, that's all you did. But my children now have experienced a whole wide variety of food and loved all food, and we eat anything so long as it's not lived ... And then once I started eating food I just loved it, and then I had kids, I started to enjoy food more and more because I had kids and I had to feed them ... I've been cooking a long time. The food of my childhood is non-existent in my life now".

Tony highlights the heightened connection between "eating properly" (almost having a culinary epiphany since moving away from his parent's influence) and becoming a father, and "having" to feed his children in a "proper" way. Articulating strong intensive parenting ideology (Hays, 1996) - of 'caring about' his children through 'caring for' them (DeVault, 1991) - Tony scorns the lacklustre food socialization style 
of his parents, particularly his mother.

Similarly, Natasha recalls that she had to teach herself how to eat healthily when she left home, with literature suggesting that the most significant erosion of intergenerational influences occurs when one leaves home (Beck and Jennings, 1991; Moore et al., 2001; Gram et al., 2015). Natasha negatively expressed that she does not want to pass on the "strange food habits" of her parents to her own children. Natasha chooses "not to carry on" her mother's routine of baking cakes and providing unhealthy, sugar-laden desserts after every meal to her children (because she has learned that sweet food is not good for the body):

"This's gonna sound really awful. But, I guess I was quite critical when I was a teenager. My mum, she's not slim. She's quite heavy, and I must have looked at her as a teenager and thought if I continue eating like you, then my body is the same ... I started to cut down on certain things. So, I learned what works with my body, and I know that I need to exercise and I now know that I need to eat healthily".

Natasha wants to make a positive change in her eating routines and those of her children. Many participants questioned the actions of their parents ("What on earth were they thinking, feeding us all that? They were hardly good parents") and recalled with remorse perceived deficiencies in their parent's parental style ("It was like they couldn't care less about us and what we ate"). Natasha purchased many books when her children were babies because she wanted to make sure that they had "the right food" and did not consume "all the sweet fruits early on". Equally, Olivia comments that she ate lots of fatty meat as a child because her mother thought fat was nutritious; and Olivia has since changed her own family's diet to consume less fat because of her new food knowledge.

Such examples signify how emotion is at the core of the process of reflexivity, in which reasoning (i.e. the need to establish healthier eating practices to develop greater wellbeing for their own children) is highly valued during the interpretation of emotions - with participants highlighting feelings of being "uncared for" during (in their eyes) deficient childhood eating experiences. The above examples help demonstrate that self-learning can be one potential force of disruption within the process of intergenerational influence (Moore et al., 2002), facilitated through the 


\section{New influencer}

Intergenerational consumption practices, as discussed, tend to alter when there is a change in family structure, such as when a family member joins/departs the family (Moore et al., 2001). This leaves some potential for the legacy of intergenerational influence to change and new behaviours to emerge/be introduced. The most powerful new influencer in intergenerational food consumption patterns is the presence of a spouse or partner. Moore et al. (2002) consider new influencer as a significant potential force for the interruption of intergenerational influence. Participants expressed that changes in food consumption habits also came about through discussion with their partner (where present) in respect to how to alter or adjust their previous food practices (at a combined level).

Our participants acknowledge that when their partner/spouse joins their family, the partner/spouse brings with him/her a different set of food consumption patterns. Claudia, for example, shows that she has adjusted her diet from being a meat-eater to eating vegetarian meals because her husband is vegetarian; however, the legacy of her parent's primary socialization actions (as carnivores) does endure, and Claudia occasionally offers her daughter meat when her husband is away from the family home:

"If I am on my own, I do it the way my parents would do it. If my husband is there, because he's out during the day, we do have the main meal in the evening. My partner is vegetarian. So, we don't normally cook with meat. But, she [daughter] does get it now and then when we are out just the two of us. And, I have the meal with meat, for example".

We recognise, however, that we are reliant on the voice of the primary food preparer captured within our study. Whereas our data highlights the dynamic at play between parent-child, the dynamic between parents in terms of which childhood eating practices are to become "household policy" in adulthood need further exploration. With Claudia's case, for example, she likes the food she ate as a child, yet the legacy of her husband's family/beliefs dominate. Although others show that mothers often 
assume a subservient position in feeding the family (DeVault, 1991), we interpret Claudia's example as part labour-saving practice. Although Claudia admits she would rather cook meat-based meals, providing vegetarian dishes for her family (which they will all eat) avoids preparing two separate meal choices.

Likewise, Tony, who became a vegetarian when he was twenty-four years old, shares that he started to learn about eating a healthy variety of vegetables because of his partner's influence (coupled with his dissatisfaction with his own parent's eating habits, recalled earlier):

"I accepted that it was reasonable for me to eat just chips, beans and something or other all the way through my life until I met people, especially my other half, from outside where I was born and realised, hmm, I have never eaten a red pepper before in my life. And so it was - my expectations changed".

Disruption in the intergenerational influence of socialization transfer can be attributed to the presence of a new influencer. But disruption can also be attributed to changes in the social context, with the younger generation of parents exposed to what has been termed heightened "market focussed health activism" (Cronin and Hopkinson, 2017, p. 2) and significant changes in the food landscape (e.g. in terms of food availability, the cost of healthy ingredients and recent public policy/social marketing campaigns that highlight issues relating to food consumption/literacy) (see, for example, Cronin et al., 2013) and heightened concerns for animal welfare (Beverland, 2014).

\section{Sustaining food practices}

Not all food socialization behaviours were abandoned. Positive emotions led to the reproduction of food practices within the participant's own family, and in such situations food choices were sustained; food recipes, preferences, and other foodrelated values or behaviours were reproduced/mimicked with their own young family, often creating warm feelings of nostalgia and fostering connection with absent family members. Frequently, parents reflect back to those consumption patterns in the forms of behavioural norms. In this section of our findings, the elicited stories focus on the motivation to continue the family's perceived style of eating. Kate, for 
example, enthusiastically continues her father's ways of preparing and consuming "healthy" food with her children:

"I learned a lot from my parents. So I learned a lot because they were interested in healthy eating, healthy food, organic and ... I think we got many recipes actually and much healthy eating from my dad. He was a really big cook, and he used to do much vegetarian food. He was very sort of into cooking, and he passed on many of his recipes then".

The transference and inheritance of recipes from generation to generation fostered positive reflection and offered participants a way to keep family stories - and members - alive ("I often cook this and say 'this is how your grandad would do it', and inevitably that would lead to stories of what he was like before he died" (Jane)). Rather than being macabre, participants celebrated such instances and traditions, reflecting an affectively charged route to intergenerational influence (Price et al., 2000).

Similarly, Sandra also feels that she would like to continue socializing her children to eat healthily in the same manner her parents adopted. Sandra adds that her mum is "the most important role model" for her regarding eating/establishing food consumption patterns, and Sandra reports that she is trying her "best" to be as good a mother:

"My parents cooked. And yes, I use the same techniques my parents used when I was young with them [my children]. Everything that I learned from 'clear up your plate' to consume many vegetables and avoid fat'.

Whereas other participants (c.f. Olivia and Jennifer) were dismissive of such food rules, Sandra favourably reminisced about time spent cooking with her mother and her food socialization style. Other participants also strongly reminisced about "cooking food from scratch", just as their parents did, reporting that they want to sustain such practices with their own families (Moisio et al., 2004). Many parents made the link between 'healthy food' as that which involves cooking "from scratch"; using ingredients freshly produced, often grown at home, as one of the practices that they have sustained, as Fran comments: 
"Well you would go by what you have been taught by your parents like we don't eat this. We never have. You know what is going in to you because you've cooked it yourself. So those are the values that you've been brought up with. Their gran - she grows far more than we do - and she will cook her own food as well, as does my mum. So I think we come from two generations of families that always cook their own stuff, so we have not changed that habit".

Such practices align with studies of intergenerational influence (see Moore et al., 2002) that suggest children tend to purchase familiar brands that they have been socialized with by their parents because it simplifies their decision-making process in a complex marketplace. These findings also suggest that preparing food 'from scratch' is one way to describe healthy food, because such cooking requires much effort and time to prepare; and it supports the highly emotionally charged norms of intensive parenting which represents the food preparer's self-sacrifice (Harman and Cappellini, 2015).

Feelings of nostalgia also supported intergenerational transfer. For example, Jane discussed that she performs her father's "fixed menu every Friday" as a "throwback to her childhood" commenting that her "kids love that on a Friday night", eating together around the dining table. Although Jane has expanded her repertoire of tastes/cooking with time, she still returns to the food that she was brought up with in the 1970s - food steeped with nostalgic feelings of happy, content family life:

"My tastes have changed over the years and become much more sophisticated because there is more accessible [food] now in Britain to a broader range of international foods. However, I think that the basic things that you eat when you are a child are those foods that you go back to in times of illness or the comfort level in them is something that is sort of inherent in you from being a child".

Spending time together during the meal (as Jane did/does every Friday evening) is reported to have significant meaning for the families recruited. Participants reflect that they like to follow the family's tradition of eating together (as encouraged by their parents). Claudia, for example, recalls sitting and eating together with her family as a child, which she thoroughly enjoyed. She adds that she is 'pleased' that her own family do the same, despite the time constraints both Claudia and her 
husband face. Maintaining collective family meals, offering family members sacred time to share each other's stories, was seen as essential to several participants, as Isabella explains:

"When I was young, I was happy with what we eat. And it's also time we spent together. And I think to have a pleasant atmosphere is another important thing for eating. We usually eat together. For me, this is everything that you have the nice atmosphere at home and that you talk to each other and you sit together. With my family, we try to do that as often as we can".

The majority of participants in this study brought their children along on grocery shopping trips as another way to sustain intergenerational influences. Participating in the family shopping is considered a dominant force in maintaining intergenerational transfers (Moore et al., 2001) within the context of food. According to the brand equity study of Moore et al. (2002), shopping styles, including shopping preferences, the mood to go shopping, and the way an individual makes decisions, are passed on between generations and are treated as a force of intergenerational influence. Hill (1970) illustrates that daughters learn how to be consumers in the marketplace by shopping with their mothers. Rachel, for example, recalls that she used to go grocery shopping with her mother as a child, pointing out that she is 'treating' her son the same (note the diluted gender norms). Rachel adds that this was how she learned to buy food in the supermarket and Fran likewise discusses that she grew up buying produce from the fresh food market in Wolverhampton with her mother, commenting that she has never "lost the habit, really".

This section of our findings highlights the positive, reminisced memories associated with food socialization that the parents reflect on from when they were young. The emotionally charged rituals of family mealtimes, accompanied grocery shopping trips and maintaining food practices handed down between generations (e.g. recipes) were laden with positive, nostalgic feelings that participants wanted to recreate with their own children.

\section{Identity of familial intergenerational food consumption}

From the parental behaviours outlined above we develop a continuum of parental food socialization styles, ranging from 'Traditionalists' to 'Improvers' to those 
labelled 'Revisionists', who exhibit differences in emotional responses to intergenerational influence and concomitant consumption behaviours (either sustaining inherited behaviours of their own parents, or disregarding such actions, forming new food socialization pathways). Reflecting on actions of the past informed how our participants socialized their own children within the context of food.

Traditionalists continue the food consumption routines of their parents with their own families without changing any food practices. There is a great deal of positive reflection and emotional nostalgia exhibited amongst such parents who are keen to emulate the parental food socialization style performed by their own parents. Recall from Kate's story her pride that her father had passed on lots of his vegetarian recipes to his children; Kate highlights that both she and her brother are now cooking using these recipes for their own families which affords them positive ways to reminisce about their own enjoyable childhood. Their food patterns remain the same since they were young. Similarly, Isabella's story of having a pleasant atmosphere during mealtime demonstrates her strong sense of positive intergenerational reflexivity: "When I was young, I was happy with what we eat. And it's also time we spent together". Such stories illustrate that traditionalists exhibit positive emotional intergenerational reflexivity and that they are happy with the food practices the previous generation established. Thus, they would like to sustain such practices with their own families (which offers an emotional connection and bond to family members, particularly those who are now deceased).

The majority of our participants are labelled Improvers. Improvers have chosen to sustain the food practices from the previous generation, whilst also changing or adapting specific food practices as they see appropriate. Recall Fran's experience that although she does not want to be a strict 'Victorian' parent, she would still "go by what you have been taught" from her parents and retains elements of her mother's ways of cooking food from scratch. Likewise, Claudia's experience also shows that she is trying to balance cooking vegetarian food for her husband and following some of her mother's (non-vegetarian) recipes, providing meat meals for her daughter from time to time. Equally, Kayla mentions that she is more relaxed about her daughter eating snacks than her parents would have been (implying that her parents advocated more restrictive ways). Although Jane was pleased with her upbringing and has not lost the habits of eating "without added sugar" products, she 
still wants her children to be able to cook after they leave home, which is the only thing her mother did not teach her (something which creates a degree of sadness on Jane's part). While certain food practices from the previous generation persist, the improvers altered others - changing as a result of learning new things about food (often bringing their parent's food styles up to date given the rise of the healthy-eating agenda) or from the presence of a new influencer. Although the improvers are largely happy and exhibit positive intergenerational reflexivity, they want to improve certain food habits that they think are better for their children to learn (improving from the past).

Our final category of parents, 'Revisionists', however, recall "shocking” food socialization experiences from their childhood (Moore et al., 2002). Revisionists appear to have made radical changes to their food consumption due to their negative intergenerational reflexivity towards the previous generation's food consumption styles/practices. They believe that these are changes for the better, similar to the intention of improvers, as participants are trying to align themselves with the notion of good parenting (Hays, 1996; Harman and Cappellini, 2014, 2015). Unlike improvers, revisionists do not retain or sustain any food practices as established by the previous generation. Tony, for example, is a revisionist parent, highlighting that he grew up as a child with poor attitudes surrounding food; and he has since become a vegetarian because of the influence from his partner and his newfound interest in food (following his move away from the family home and what he labels a "food awakening"). Rebecca has also changed her childhood food habits because she did not like how her father socialized her (recall the naughty box story and her feelings of guilt at eating hidden, unhealthy products) and as a result of her husband's healthy eating influence. Thus, Rebecca has changed her food practices in the hope of encouraging her son to establish healthy eating habits: "I didn't want him to have to worry about his weight ... I just want him to be happy". Similarly, Natasha mentions that she does not want to follow her mother's style of eating because she, as a parent, is more concerned with the health and well-being of her family (unlike her mother reportedly was when Natasha was a child). Such stories show that revisionists want to adjust or change food habits because they have "better intentions for children". 


\section{Discussion}

This study adopts a rather different approach in exploring temporal dimensions of intergenerational influence using the lens of emotional reflexivity within the context of food socialization. The findings suggest that the intergenerational reflexivity of parents, as the most powerful socialization agent of children (Hughner and Maher, 2006; Marshall et al., 2007), plays a crucial role in shaping children's food socialization processes. We posed one central research question: “are today's parents drawing from what they learned as children from their parents within their own food socialization practices?" We find that parents reflexively enact the legacy of the past to guide their current food practices. Intergenerational reflexivity informs how participants (re-)produce their current food socialization practices, as informed, in turn, by how their parents socialized them during their childhood. The findings, therefore, contribute to socialization theory in relation to the classical model of socialization offered by Moschis and Churchill (1978) in that intergenerational reflexivity on the part of the socialization agent (family or parents) is another valuable factor that should be included in future studies of consumer socialization.

Our findings demonstrate support for Moore et al. (2001) and Moore et al. (2002) in that intergenerational influences appear to persist well into adulthood (in terms of familial food socialization practices, at least). Where participants recall positive emotional reflexivity associated with childhood food consumption, intergenerational influence endures. The impact of intergenerational influence tends to be fluid over time, which can either maintain or dismiss certain habits in consumption experiences (Moore et al., 2002). The findings extend our understanding of the temporal dimensions of intergenerational influence within families, suggesting that parents take inspiration (in both positive and also dismissive ways) from what they learned about food as a child from their parents to inform their own actions and behaviours. We offer a contiunnum of parental food sozialization tendencies which reflect behaviour that sustains and reproduces behavioural patterns of the past to behaviours which are radically different from those performed by the previous generation of parents. We respond to calls for further research that investigates the dynamics of intergenerational transfers amid the context of family food socialization (Moore et al., 2017). 
The stories of our participants reveal the important role emotional reflexivity plays in this process, whereby participants either retain or alter their food socialization practices in response to feelings and interpretations of themselves (i.e. whether they are happy with their previous food practices or perceive that previous food practices are out-dated and unhealthy) as well as their interpretations of how others feel about their circumstances (i.e. the relationships with their parents or how they think society would look to them as a 'good' parent in providing healthy food for their children). Holmes (2010) suggests that emotional reflexivity tends to be recognisable when it comes to love and care, as our findings illustrate. Such elicited stories respond to the calls made for research which extends the use of emotional reflexivity within consumer research (in forming children's food socialization practices) (Holmes, 2015), and demonstrates that participants use intergenerational reflexivity to "reflect in distinctive ways upon their experiences ... with others, as well as their sense of self' (Mason, 2004, p.167).

Stories of intergenerational reflexivity on food consumption show that intergenerational reflexivity plays a vital role in the continuance of a family's food consumption practices from one generational to the next. As Holmes (2015) highlights, emotional reflexivity is vital in the process of social reproduction, and the emotional connection of the participant's childhood food practices leads to the reproduction of such habits with their children. Sandra is an obvious example to illustrate the 'sustaining' of food practices from her parents as she follows her mother's ways of cooking for her children. Sandra's elicited story has shown that she has positive emotional intergenerational reflexivity (love and respect for her mother) with a strong intention to emulate her mother's food consumption practices with her offspring. It is clear that she is happy with her familial food upbringing/socialization.

This is not to say that emotional reflexivity only revolves around social reproduction or retaining food habits/patterns. Although traditional reflexivity tends to focus on changes rather than maintaining habits, our findings illustrate that not only do parents 'sustain' their previous food practices with their children, but that parents can also 'disregard' certain food habits. When parents display negative emotional reflexivity associated with the previous generation's food practices, they choose to disregard such food practices with their children. During dialogue parents have about their food practices with their children, parents highlight that they are deliberately 
making decisions to abandon their childhood food practices, as shown in the case of Tony who expresses great bitterness towards his mother's (poor) food practices and has chosen to 'disregard' such behaviours with his children. Interestingly, Finch (2007) highlights that parents often portray legacy stories as in opposition/to help explain how they now behave. This supports Tony's case in that he perceives he was "uncared for" as a child by his mother (mainly as a result of the poor food she prepared for him), fuelling anger towards the way he was raised. Thus, Tony consciously moves away from what he perceives as negative food practices performed by his mother, fuelled by his interest in vegetarian food and by the presence of a new influencer (his partner). Tony's example clearly illustrates that emotion (i.e. a feeling of being uncared for) is at the core of reflexivity, in which cognitive reasoning (i.e. to have healthier eating patterns) is high and rises above the automation of emotional responses.

As suggested by Moore et al. (2002), intergenerational influences can be disrupted due to the presence of a new influencer; and in this study, the spouse or partner (c.f. the example of Tony, above) emerged as a primary influencer to restructure/blend familial food practices. Other stories of 'disrupting' the previous generation's food practices include resistance to the legacy of parental norms (Jonathan, for example, recounted stories of being forced to eat food he disliked as a child, and Fran does not want to emulate her 'Victorian' parents). We also identify how other social factors - such as changes in food literacy and heightened awareness of nutrition (Cronin and Hopkinson, 2017) work to encourage participants to redress perceived deficiencies in the parental food socialization styles performed by their parents: "each generation's perception of eating well is developed through evolving schema for making food choices learnt through changing social and cultural processes over time" (Delaney and McCarthy, 2014, p. 106). Although social factors are acknowledged to help explain possible intergenerational shifts, the legacy of childhood socialization remains strong (recall Jane's story that even though she has the luxury of a wider variety of food to offer her own children, she often returns to the food of her childhood).

The stories of parental aspirations to socialize their children to eat healthily demonstrates that parents are trying to align themselves with the ideology of intensive parenting discourse, involving parental displays of "good parenthood" (Finch, 2007; Harman and Cappellini, 2015). It is possible that such an ideology/sense of parents 
"on display" (Harman and Cappellini, 2015) is heightened among our participant's generation, and we recognise that this is a pertinent area for future research. Family identity can, however, be passed on and reinforced through cultural transmission, in which each generation tries to differentiate itself from another generation by designing its own identity (Epp and Price, 2008; Knight et al., 2014).

Other opportunities for further research exist. Future research would benefit from more closely examining differences between gender, with others (see Del Bucchia and Penaloza, 2016) highlighting differences amongst mothers and fathers in food provision. The recent study of Chowbey (2017), as a second example, shows that mothers tend to resist their submissive gender position within the household by conveying their controlling position through the food they provide; this represents a ripe area for closer exploration in future research. Similarly, we capture the voice of the main food preparer in her/his family. We recognize that it would be fruitful to capture and represent the multiple voices within the family unit (including those of children) in order to capture the dynamics at play between which parent's (in the context of two-parent families) primary socialization dominates/is regarded as family food policy (and how this is established - and possibly blurred given the rise of family disruption and fluidity of family membership within and between sites of consumption).

The findings from this research carry important implications for public health interventions, social initiatives and marketing campaigns that aim to encourage parents to model healthy eating behaviours. Our participants are largely aware that certain food socialization tendencies performed by the generation before them are not healthy for their own children. However, equally our research highlights the need to explore the family as a complex and dynamic nexus of influences and histories. Healthy eating campaigns are likely to be received differently by either parent, taken onboard or disregarded by individuals in different ways within the family setting. Granted, our data points towards a distancing of parental practices from the past, but where there is spousal conflict (see Chowbey, 2017) - not explored within this study making healthier food choices between spouses/co-parents may be harder to achieve (or encourage). Accordingly, research is called for that explores such issues within the complex family setting. 
Establishing healthy eating patterns through socialization within families could help children move away from the obesity epidemic (Moore et al., 2017) and might, hopefully, transfer to the next generation. We note that positively charged emotional behaviours (e.g. cooking food from scratch, growing one's own produce) resonated and endured most with our participants (representing a possible theme for future healthy-eating campaigns). This helps add support to the notion that healthy eating campaigns linked to constraint prove ineffective (Poulain, 2009), so links to the social dimensions of food (e.g. the positive triggered feelings of nostalgia/family connections and caring for your family through appropriate nutritional intake) may prove beneficial in the promotion of healthy-eating campaigns.

\section{Conclusion}

As parents are the most powerful socialization agents for children, children have limitless learning opportunities surrounding food that stems from parental food socialization and actions. The legacy of such learning suggests food preferences/behaviours can endure and inform food consumption in adult life. This study provides a deeper insight into to how emotional reflexivity (Holmes, 2015) and temporal elements of intergenerational influence (Moore et al., 2002, 2017) impact familial food socialization, much lacking in the existing literature. In this study, emotional reflexivity is utilised among participants to make sense of their parental role in providing food to their own family. The participants draw on their emotional reflexivity in recalling previous food practices (learned/experienced as a child by their parents), which informs whether they would enact - or disregard - the same patterns of food practices/socialization with their own children. The study contributes to our understanding of the role intergenerational influence plays within the process of food socialization, exploring how practices from the past (experienced during primary socialization) could be repeated or discontinued in the present (Knight et al., 2014). 


\section{References}

Adkins, L. (2000), “Objects of Innovation: Post-occupational Reflexivity and Retraditionalisations of Gender", in Ahmed, S., Kilby, J., Lury, C., McNeil, M. and Skeggs, B. (Ed.), Transformations: Thinking through Feminism, pp.25972. London: Routledge.

Alm, S. and Olsen, S. O. (2016), "Using photo interviews to explore children's food preferences", International Journal of Consumer Studies, (July 2016), pp.1-9.

Ayadi, K., and Bree, J. (2010), "An ethnography of the transfer of food learning within the family", Young Consumers: Insight and Ideas for Responsible Marketers, 11(1), pp.67-76.

Beck, U. (1992), Risk Society, Sage, London.

Beck, P.A. and Jennings, M. K., (1991), "Family traditions, political periods, and the development of partisan orientations", The Journal of Politics, 53(3), pp.742763.

Belk, R., Fischer, E., and Kozinets, R. V. (2013), Qualitative consumer and marketing research. Sage.

Bettany, S., Kerrane, B. and Hogg, M. (2014), "The material-semiotics of fatherhood: the co-emergence of technology and contemporary fatherhood", Journal of Business Research, 67 (7), pp.1544-1551.

Beverland, M., (2014), "Sustainable eating: mainstreaning plant-based diets in developed economies", Journal of Macromarketing, 34(3), pp. 369-382.

Birch, L. L., and Fisher, J. O. (1998), "Development of eating behaviors among children and adolescents", Pediatrics, IHI, pp.539-549.

Birch, L. L., Fisher, J. O., Grimm-Thomas, K., Markey, C. N., Sawyer, R., and Johnson, S. L. (2001), "Confirmatory factor analysis of the Child Feeding Questionnaire: a measure of parental attitudes, beliefs and practices about child feeding and obesity proneness", Appetite, 36(3), pp.201-210.

Birch, L.L., Savage, J.S. and Ventura, A. (2007), "Influences on the development of children's eating behaviours: from infancy to adolescence", Canadian Journal of Dietetic Practice and Research, 68(1), pp.1-56.

Block, L. G., Grier, S. a, Childers, T. L., Davis, B., Ebert, J. E. ., Kumanyika, S., Laczniak, R. N., Machin, J. E., Motley, C. M., Peracchio, L., Pettigrew, S., Scott, M. and van Ginkel Bieshaar, M. N. . (2011), "From Nutrients to Nurturance: A Conceptual Introduction to Food Well-Being", Journal of Public Policy \& Marketing, 30(1), pp.5-13.

Braun, V., and Clarke, V. (2013), Successful qualitative research: A practical guide for beginners. Sage.

Burkitt, I. (2012), "Emotional Reflexivity: Feeling, Emotion and Imagination in 
Reflexive Dialogues", Sociology, 46(3), pp.458-472.

Cabrera, N. J., Tamis-LeMonda, C. S., Bradley, R. H., Hofferth, S. and Lamb, M. E. (2000), "Fatherhood in the twenty-first century", Child Development, 71, pp.127-136.

Carlson, L., Walsh, A., Laczniak, R. N. and Grossbart, S. (1994), "Family Communication Patterns and Marketplace Motivations, Attitudes, and Behaviors of Children and Mothers", Journal of Consumer Affairs, 28(1), pp.25-53.

Childers, T. L. and Rao, A. (1992), "The influence of Familial and Peer-Based Reference Groups on Consumer Decisions", Journal of Consumer Research, 19 (September), pp.198-211.

Chowbey, P., (2017), "What is Food Without Love? The Micro-politics of Food Practices Among South Asians in Britain, India, and Pakistan", Sociological Research Online, 22(3), pp.165-185.

Clark-Ibáñez, M., (2004), "Framing the social world with photo-elicitation interviews", American behavioral scientist, 47(12), pp.1507-1527.

Cronin, J. and Hopkinson, G. (2017), "Bodysnatching in the marketplace: marketfocused health activism and compelling narratives of dys-appearance", Marketing Theory.

Cronin, J., McCarthy, M., Brennan, M. and McCarthy, S. (2013), "The bigger society: considering lived consumption experiences in managing social change around obesity", European Journal of Marketing, 48(9/10), pp.1558-1578.

Delaney, M. and McCarthy, M. (2014), "Saints, sinners and non-believers: the moral space of food", Appetite, 73, pp.105-113.

Denzin, N.K. (1984), On Understanding Emotion. San Francisco, CA: Jossey-Bass.

Del Bucchia, C. and Penaloza, L. (2016), "“No, I won't eat that!" Parental selftransformation in clashes of role enactment and children's will", Journal of Business Research, 69 (1), pp.145-154.

DeVault, M. (1991), Feeding the family: The social organization of caring as gendered work, University of Chicago Press, Chicago.

Dotson, M. J. and Hyatt, E. M. (2005), "Major influence factors in children's consumer socialization", Journal of Consumer Marketing, 22(1), pp.35-42.

Ekström, K. M. (2006), "Consumer Socialization Revisited”, Research in Consumer Behavior (Published online), pp.71-98.

Epp, A. M. and Price, L. L. (2008), "Family Identity: A Framework of Identity Interplay in Consumption Practices", Journal of Consumer Research, 35(1), pp.50-70.

Finch, J. (2007), “Displaying Families”, Sociology, 41(1), pp.65-81. 
Giddens, A. (1990), The Consequences of Modernity, Palo Alto, CA: Stanford University Press.

Giddens, A. (1992), The transformation of intimacy: Sexuality, love and eroticism in modern societies. Palo Alto, CA: Stanford University Press.

Gram, M. (2015), "Buying Food for the Family: Negotiations in Parent/Child Supermarket Shopping: An Observational Study from Denmark and the United States", Journal of Contemporary Ethnography, 44(2), pp. 169-195.

Gram, M., Hogg, M., Blichfeldt, B. S. and MacLaran, P. (2015), "Intergenerational relationships and food consumption: the stories of young adults leaving home", Young Consumers, 16(1), pp.71-84.

Grier, S. A., and Moore, E. S. (2012), "Tackling the Childhood Obesity Epidemic”, in Mick, G. M., Pettigrew, S., Pechmann C., and Ozanne, J. L. (Ed.), Transformative Consumer Research for Personal and Collective Well-Being, pp.303-332.

Gross, N. (2005), “The Detraditionalization of Intimacy Reconsidered”, Sociological Theory, 23(3), pp.286-311.

Grønhøj, A. and Thøgersen, J. (2009), "Like father, like son? Intergenerational transmission of values, attitudes, and behaviours in the environmental domain", Journal of Environmental Psychology, 29(4), pp.414-421.

Harman, V. and Cappellini, B. (2014), "Unpacking fun food and children's leisure: mothers' perspectives on preparing lunchboxes", Young Consumers, 15(4), pp.312-322.

Harman, V. and Cappellini, B. (2015), "Mothers on Display: Lunchboxes, Social Class and Moral Accountability", Sociology, pp.1-32.

Harper, D. (2002), "Talking about pictures: A case for photo elicitation", Visual Studies, 17(1), pp.13-26.

Hart, L., Damiano, S., Cornell, C. and Paxton, S. (2015), "What parents know and want to learn about healthy eating and body image in preschool children", $B M C$ Public Health, 15, pp.1-13.

Hays, S. (1996), The cultural contradictions of motherhood, Yale University Press, New Haven.

Hill, R. (1970), Family development in three generations, Schenkman, Cambridge, MA.

Holmes, M. (2010), “The Emotionalization of Reflexivity”, Sociology, 44(1), pp.139154.

Holmes, M. (2015), "Researching emotional reflexivity", Emotion Review, 7(1), pp.61-66.

Hughner, R. S. and Maher, J. K. (2006), "Factors that Influence Parental Food 
Purchases for Children: Implications for Dietary Health", Journal of Marketing Management, 22(9-10), pp.929-954.

John, D. R. (1999), "Consumer socialization of children: A retrospective look at twenty-five years of research", Journal of consumer research, 26(3), pp.183213.

Judd, S. M., Newton, J. D., Newton, F. J., and Ewing, M. T. (2014), "When nutritional guidelines and life collide: family fruit and vegetable socialisation practices in low socioeconomic communities", Journal of Marketing Management, pp.1-29.

Kerrane, B., Bettany, S. M., and Hogg, M. K. (2014), "Revisiting contemporary issues in family consumption", Journal of Marketing Management, 30(15-16), pp.1527-1532.

Knight, A., Connell, R. O. and Brannen, J. (2014), “The temporality of food practices: intergenerational relations, childhood memories and mothers' food practices in working families with young children", Families, Relationships and Societies, 3(2), pp.303-318.

Kral, T. V. E. and Rauh, E. M. (2010), "Eating behaviors of children in the context of their family environment", Physiology \& Behavior. Elsevier Inc., 100(5), pp.567-573.

Lawlor, M.A., and Prothero, A. (2011), "Pester power - A battle of wills between children and their parents", Journal of Marketing Management, 27(5-6), pp.561-581.

Lupton, D. (1994), "Food, memory and meaning: the symbolic and social nature of food events", The Sociological Review, 42(4), pp.664-685.

Marshall, D., O'Donohoe, S. and Kline, S. (2007), "Families, food, and pester power: Beyond the blame game?", Journal of Consumer Behaviour, 6, pp.164-181.

Marshall, D. and O'Donohoe, S., (2010), "Children and food", in Harris, P. (Ed.), Understanding children as consumers, Sage, London, pp.167-183.

Mason, J., (2004), "Personal narratives, relational selves: residential histories in the living and telling", The Sociological Review, 52(2), pp.162-179.

Minahan, S. and Huddleston, P. (2010), "Shopping with mum - mother and daughter consumer socialization", Young Consumers, 11(3), pp.170-177.

Moisio, R, Arnould, E, and Price, L, (2004), "Between mothers and markets: constructing family identity through homemade food", Journal of Consumer Culture, 4(3), pp.361-84.

Moore, E. S. (2010), Childhood socialization and intergenerational influences, Wiley International Encyclopedia of Marketing. 3.

Moore, R. L. and Moschis, G. P. (1980), "Social interaction and social structural determinants in adolescent consumer socialization", Advances in Consumer 
Research, 7, pp.757-759.

Moore, E. S., Wilkie, W. L. and Alder, J. A. (2001), "Lighting the Torch: How Do Intergenerational Influences Develop?", Advances in Consumer research, 28, pp.287-293.

Moore, E. S., Wilkie, W. L. and Desrochers, D. M. (2017), "All in the Family? Parental Roles in the Epidemic of Childhood Obesity", Journal of Consumer Research, 43(September), pp.824-859.

Moore, E. S., Wilkie, W. L. and Lutz, R. J. (2002), "Passing the Torch: Intergenerationai influences as a Source of Brand Equity", Journal of Marketing, 66(April), pp.17-37.

Moschis, P. G. and Churchill, A. G. (1978), "Consumer Socialization: A Theoretical and Empirical Analysis on JSTOR”, 15(4), pp.599-609.

Moschis, G. P., and Moore, R. L. (1979), "Decision Making Among the Young: A Socialization Perspective", Journal of Consumer Research, 6(Special Issue on Consumer Decision Making (September), pp.101-112.

Nicklas, T. A., Baranowski, T., Baranowski, J. C., Cullen, K., Rittenberry, L., and Olvera, N. (2009), "Family and child-care provider influences on preschool children's fruit, juice, and vegetable consumptions", Nutrition Reviews, 59, pp.224-235.

O'Connor, T. G. and Scott, S. (2007), Parenting and outcomes for children, Joseph Rowntree Foundation, York.

O’Malley, L., and Prothero, A. (2006), "Consuming Families: Marketing, Consumption and the Role of Families in the Twenty-first Century", Journal of Marketing Management, 22(9-10), pp.899-905.

Palmer, M., Larkin, M., de Visser, R., and Fadden, G. (2010), "Developing an Interpretative Phenomenological Approach to Focus Group Data", Qualitative Research in Psychology, 7(2), pp.99-121.

Pedersen, S., Grønhøj, A., and Bech - Larsen, T. (2012), "Family members' roles in healthy - eating socialization based on a healthy - eating intervention", Young Consumers, 13(3), pp.208-223.

Peters, J., Parletta, N., Lynch, J. and Campbell, K. (2014), “A comparison of parental views of their pre-school children's "healthy" versus "unhealthy" diets. A qualitative study", Appetite, 76, pp.129-136.

Poulain, J. P. (2009). Sociologie de l'obésité, France, Presses Universitaires de France.

Price, L., Arnould, E. and Curasi, C. (2000), “Older consumers' disposition of valued possessions,” Journal of Consumer Research, 27, pp.179-201.

Russell, C.G. and Worsley, A., (2013), "Why don't they like that? And can I do anything about it? The nature and correlates of parents' attributions and self- 
efficacy beliefs about preschool children's food preferences", Appetite, 66, pp.34-43.

Smith, J., Flowers, P., and Larkin, M. (2009). Interpretative Phoneomological Analysis: theory, method and research, Sage, London.

Sunderland, P. L., and Denny, R. M. T. (2007), Doing anthropology in consumer research, Left Coast Press, Walnut Creek, CA.

Thompson, C. J., Locander, W. B., and Pollio, H. R. (1990), “The lived meaning of free choice: an existential-phenomenological description of everyday consumer experiences of contemporary married women", Journal of consumer research, pp.346-361.

Ward, S. (1974), "Consumer Socialization”, Journal of Consumer Research, 1(September), pp.1-14.

Wardle, J. (1995), "Parental Influences on Children's Diets", in Proceedings of the Nutrition Society, Cambridge, UK, 54(3), pp.747-758.

White, L. and Davis, T., (2006), “Children and Snack Foods: Is There a Relationship between Television Viewing Habits and Nutritional Knowledge and Product Choice?", Asia-Pacific Advances in Consumer Research, 7, pp.277-282. 


\section{Learning from the past? An exploratory study of familial food socialization processes using the lens of emotional reflexivity}

\section{Response to reviewer comments}

We would like to sincerely thank both reviewers for their comments and suggestions to help improve our manuscript. We believe that such constructive comments have identified important areas to be strengthened in our paper. We now respond to the minor comments both reviewers have highlighted. We present, below, a point-by-point account of how each comment was addressed in our manuscript. By addressing the issues the reviewers highlight, we feel that our paper is much stronger; and we would like to thank both reviewers again for their time and thought that has been given to our manuscript. We also appreciate the opportunity that has been given to us to present our revised manuscript to you again.

\section{Reviewer 1 Comments \\ (Recommendation: Minor Revision)}

\section{Originality: Does the paper contain new and significant information adequate to justify publication?}

\section{Yes this is an interesting discussion of food habits}

Thank you very much for the compliment. We hope that our paper will contribute to the existing knowledge on parental roles in socializing children within the context of food choice/preferences, and in terms of understanding how the legacy of the past helps inform parental food socialization practices through the lens of intergenerational reflexivity.

2. Relationship to Literature: Does the paper demonstrate an adequate understanding of the relevant literature in the field and cite an appropriate range of literature sources? Is any significant work ignored?

\section{A better acknowledgement that we know parents parent how they were parented would be appropriate.}

Thank you for highlighting this shortcoming in our manuscript. We have added coverage of this all-important point within our revised literature review section. Specifically, we add the following comment in order to address your recommendation:

"In relation to parenting, emotional reflexivity has been used (implicitly) to explain how parents draw on "emotions to navigate their path, especially when facing new situations or ways of living" (Holmes, 2015, p. 61). Reflection on the past (i.e. the roles/actions of their own parents) infuse actions and behaviours of the present. Support exists, for example, to suggest that the parental style an individual adopts is likely shaped and influenced by the role played by his/her own parent(s), in both positive and negative ways (see, for example, Carlson et al., 1994; Bettany et al., 2014)” 
Thank you for highlighting this; in wanting to show the need for this research context we were a little naïve in how we demonstrated the significance of our study in the earlier draft.

3. Methodology: Is the paper's argument built on an appropriate base of theory, concepts or other ideas? Has the research or equivalent intellectual work on which the paper is based been well designed? Are the methods employed appropriate?

Method was interesting and thorough

Thank you.

4. Results: Are results presented clearly and analysed appropriately? Do the conclusions adequately tie together the other elements of the paper?

For the most part yes - see my comments

Thank you for your valuable comments (please see our responses to your comments, below).

5. Practicality and/or Research implications: Does the paper identify clearly any implications for practice and/or further research? Are these implications consistent with the findings and conclusions of the paper?

Practical policy implications from this research topic seem a little stretched; perhaps there can be papers with a contribution elsewhere.

Thank you for your comment. We have re-worked the section, which covers the practical significance of our work - although we acknowledge your comment that practical contributions may be offered elsewhere/beyond this paper. We draw on the guidance offered by Reviewer 2 and her/his suggestion of brining spousal conflict in to discussions of practical value to this work.

6. Quality of Communication: Does the paper clearly express its case, measured against the technical language of the fields and the expected knowledge of the journal's readership? Has attention been paid to the clarity of expression and readability, such as sentence structure, jargon use, acronyms, etc.

Well written and expressed.

Thank you for your compliment on our paper's presentation.

Reviewer 1 Comments for the authors of European Journal of Marketing manuscript ID EJM-10-2017-0694 entitled "How do parents teach their children about food? An exploratory study of food socialization processes using the lens of intergenerational reflexivity"

Thank you for the opportunity to review "How do parents teach their children about food?" This is an interesting and well-written study that relates how parents can have positive or negative recollections of their childhood eating patterns and how they 
reproduce the more positive elements and re-configure the negative aspects. This study would make a good contribution to the special issue on food.

Thank you very much for your compliment. This means a lot to us.

The following comments are made in the spirit of honing the contribution that this study makes and clarifying some of the key ideas herein.

In the introduction intergenerational emotional reflexivity begins the 3rd paragraph, however, the specific use of emotional reflexivity has not been properly introduced to the reader. It would be easier on the reader if you introduce the concept of emotional reflexivity and then expand to its relevant to intergenerational transmission.

We agree. We have now responded to this comment by rearranging the order of the concepts presented within the introduction part; and we define the concept of emotional reflexivity when it is first used:

"Emotional reflexivity "refers to the intersubjective interpretation of one's own and others' emotions and how they are enacted" (Holmes, 2015, p. 61) and offers useful guidelines to parents to either continue or discontinue their own parents' food practices with their children (through intergenerational influence). Emotional reflexivity, thus, allows individuals to navigate a 'new path', representing a useful theoretical lens through which to explore how the actions of the previous generation work to inform current food socialization processes".

We have also reworked our coverage of emotional reflexivity within the section of the literature review that covers intergenerational influence/emotional reflexivity. Thank you for bringing this to our attention.

Later in the literature review p5/6 I would like to see more explanation of how emotion is "at the heart of the reflexive process" because while emotion is entangled in how we behave, it is our propensity for reflection that allows us to engage with behaviour change and to "rise above" the automaton of emotional responses that is immaturity or childishness (although parental "impulsivity" is suggested in the introduction (p3)). For example, to be able to review the recent evidence on the pernicious role of sugar in the modern diet and avoid finishing meals with sugary deserts, which were common practice in other British generations.

If emotional reflexivity goes beyond self-reflection to include practices bodies and emotions (p6) then these elements are neglected in this study and not in the evidence presented. Perhaps the connection made was around table manners and the punitive role of cleaning plates, and emotional reflexivity opened a space to challenge the table manners of the past. Rather than doubting the value of the theory I think the order of presentation and the weight of explanation could be altered to better reflect the thinking of the authors. 
Thank you for your comments which highlight the need for (1) a greater explanation/articulation of emotional reflexivity within the literature review; and (2) a stronger articulation of how emotion informs our findings section. We have now re-worked our coverage of emotional reflexivity within the relevant section of our literature review illustrating how emotional reflexivity goes beyond self-reflection in which people try to understand their lives according to their situations. We highlight a recent study on fathering by Bettany, Kerrane and Hogg (2014) which demonstrates this theory in use. In their study, Bettany et al. (2014) show that the new fathers involved in their study reflect heavily on the role played by their own fathers and worked this reflection in to their performance of fatherhood (albeit with minimal success). We hope that this better communicates how emotional reflexivity is tied up in reflection - as you rightly signal - but that such reflection can lead to practical change in behaviour (in our case that given parents were unhappy with the style of parenting performed by their own parents, they modified their own parenting as a consequence).

We now also work such notions more explicitly within/across our findings section. The section of our findings that you allude to - on the "Victorian" style of parenting (e.g. the need to clean their plates, eat food they did not like) that many of our participants often recalled with dismay and negative emotion - was the perfect place to highlight such emotional baggage. Within the findings section, we illustrate that emotional reflexivity has opened the space to challenge the table manners of the past (as you suggest), in which reflexivity goes beyond mere self-reflection (leading to action/change). The participants have altered their previous practices according to their reasoning based on their emotions and emotions of others (their own children). Thus, they seem to be taking conscious steps towards not forcing their children to clean their plates/eat food they dislike (in ways they did not have the luxury of). Thank you so much for pointing this out to us.

Again, following your insightful comment we have re-ordered our findings section in order to better communicate the role emotion plays within our findings. We have placed more data within the finding section itself to stress the emotional reflections that were uncovered. Given the focus on emotional reflexivity this seems a very sensible course of action - so thank you for suggesting this revision to us!

Finally, I wonder if we really do lack understanding of how parents form/shape food practices. Seems to me the parents shop and cook and then most often demand the food is eaten, particularly in the under 12 age group, as related by your participants. It is acknowledged that moving away from parental control to live separately is a source of change.

We now see that the word choice we used for claiming the gap (i.e. 'great deal') was too strong. In our revisions we have toned our expression down, and we use softer words/expression to help highlight our points throughout our manuscript.

The method is particularly interesting and diverse; however, I am wondering how 8 men and 22 women makes "parenting". With more than 2 thirds of the sample women, 
and of those 6 are housewives (I assume you mean full time and unpaid - there are no men in that position), there is an overlooked narrative here about mothering that is being neutralised to "parenting". I would like a much stronger defence of this oversight.

We feel that you raise a very important and sensitive issue, which we, too, have grappled with for some time. Our intention was to principally recruit the primary food preparers of each family - following the approach taken by Judd et al. (2014). Like Judd et al. (2014), and others who have explored issues relating to food/food socialization within the family setting, our sample is relatively skewed to include more mothers $(n=22)$ than fathers $(n=8)$. Although exploring gendered food practices is not the main focus of our work, like you, we did feel uneasy at 'neutralising' the strong motherhood role/voice to 'parenting' alone. That said, we also feel uneasy with ignoring/disregarding the voices of the fathers we have recruited (and we recognise the growing role that fathers play within contemporary family life - see, for example, Wall and Arnould, 2007; Harrison and Gentry, 2007; Gentry and Harrison, 2010; Banister and Kerrane, 2017). As such, 'parenting' appears to be the most applicable label to use here, despite the majority female sample. We thank you for highlighting this allimportant point. In our methodology section we signal the above - and that here we capture the actions of the self-identified primary food preparer of the family (regardless of gender). We also acknowledge that others have identified gender differences between mothers/fathers in the context of food, which is beyond the scope of the current manuscript. We again return to this all-important point within the directions for future research section.

On this tack, another shortcoming is the lack of discussion or acknowledgement of the dynamic between parents over whose childood eating patterns are to be the "household policy". To be fair, the new influencer as partner is a section, but the inter-personal power dynamics are underplayed (Claudia's betrayal of her partner's values by having meat meals with her daughter). Or perhaps the "intensive" parent is in actuality the intensive mother. Only the power plays between parents and children over food are noted.

This is a very pertinent point to recognise. Clearly, we are grounded by the data that was offered by our participants, the primary food preparers of their family. We recognise this potential shortcoming of our work, recommend that this be considered in future research, but also offer a little more commentary where we can within the 'new influencer' section of our findings. At this point we show the triggers for potential disruption - the presence of a new partner/spouse, which also offers a neat way to offer other potential causes for disruption (e.g. changes in the food landscape/literacy). We embed this discussion within the vegetarian food choices of one of our participants, Claudia, yet this vegetarian food preference seems to endure from her husband's family. Thank you for bringing this to our attention, and we hope we have now responded to your comment.

Through the findings there is a quite neutral unacknowledged stance towards the social context. However, there are important contextual elements at play here. Food production, food availability, food accessibility, cost of healthy options as against food 
fads, food shortages, and then more recent developments such as public policy and social marketing around obesity, food quality, and food quantity. Much of the findings and discussion overlook potential shifts in the context between generations, or perhaps more importantly the lack of shifts in parental food choices across generations despite contextual changes (i.e. nostalgia and taste p14, or healthy eating p11 \& 13). Other impacts could have influenced 'self-learning' such as social capital, travelling, increased food varieties due to better logistics and a global marketplace and migration. Some explanation of how or why these are not in play would be useful. This is relevant to the discussion section too.

Thank you for pointing this out to us. Within our revised findings section, we now explicitly highlight that disruption in the transfer of intergenerational food socialization behaviours could also be trigged by the increased exposure of the younger generation of parents to specifically the factors that you highlight (e.g. heightened concerns surrounding obesity, healthy eating and a potentially privileged position of the younger parents, in comparison to the older generation). We also refer to such factors within the 'self-learning' section of our findings, which you suggest; and within the 'new influencer' category.

We now also allude to potential differences within the social context between/across the generations within our discussion section. Thank you for suggesting this revision.

There are some ideas that I find difficult to sustain - for example "finishing off" the $2 \mathrm{x}$ 2 model with a section that has "no participants", 'neglecters' seems superfluous and quite judgemental. A typology that has 3 positions on a continuum from Traditional through Improvers to Revisionists seems adequate, and describes the data as presented.

Thank you very much for your comment on this. With reflection, we completely agree. The matrix does offer a neat sense of how our data 'fits' within a given category, but clearly our work (as with other qualitative studies) does not always fit with neatness. Following your sensible suggestion, we have removed coverage of the matrix, and instead present a continuum of parental food types following your guidance. Thank you for making this suggestion to us.

The discussion returns to reflexivity citing Giddens who identified the increased need for social actors to be reflexive due to the increase in rapidity of change and the increase in social expectations for self-reliance (in contrast to the lack of change and reliance on community approval of previous eras). I am not convinced that Giddens has been used appropriately here but perhaps some further detail can develop the distinctions.

We have removed coverage of Giddens from within the discussion section. 
The label of 'self-dislike' does not seem to apply to the disrupting stories (p26). The participants are not disliking their 'self' - they were rejecting the application of parental power that demanded compliance with either finishing plates of food or table manners.

Thank you so much for pointing this out. We now revise the label to resistance to the legacy of parental norms, which best reflects the findings as well as the comment you have pointed out. Thank you for bringing this to our attention.

Lastly, the public health implications seem to be quite limited - these parents care about their children's healthy eating and are sustaining good habits and revising bad habits. This paragraph does not seem to tie into the narrative of the paper up to this point.

Thank you for your comment. We have now reworked the sentence and incorporated the implication of the research based on your suggestion to include the power plays between parents and co-parents within the food socialization practices. We also draw on the recommendations of Reviewer 2 who offers advice - below - in terms of this element of our work.

A couple of quibbles over expression - really (?) a "great deal" is unknown about the role parents play in forming family food socialization? (p2) that seems to be overstatement especially if nutrition and sociology are to be considered. Also, is it really that much of a stretch for common sense to realise that parents draw on how they were parented, and that might also encompass food preparation. To reveal the lack of astonishment would be to reverse the idea (deconstruct if you will). Why would you expect anything else?

Thank you for this comment we have reworked the gap we claim and take out the expression 'great deal'. In our eagerness to show the importance of this topic we may have been too grand with our claims. We have now toned-down the expressions we use within the introduction section, whilst simultaneously recognising gaps in understanding within this field. Clearly, we feel that such a gap exists (and we offer examples from the literature that suggests that we need to know more about food socialization, and in particular how current parents use insight from their own parents in their parental socialization style). This is a theme that we also address within the literature review section. Thank you for signalling our over-zealous expression (now rectified).

Overall, though, this paper makes an interesting contribution and I wish you well with its progress.

We sincerely thank you for the highly constructive nature of your comments. We have attended to each of these, and the manuscript is now much stronger as a result of your points. We thank you for your time - and for your good wishes. 
Reviewer 2 Comments

(Recommendation: Minor Revision)

1. Originality: Does the paper contain new and significant information adequate to justify publication?

This paper explores how participants' food experiences in their own childhood influences their current practices and ways of thinking about food as parents. This is a much-needed contribution. The paper is original in its employment of emotional reflexivity and the typology generated (figure 2).

Thank you very much for your compliment. This means a lot to us.

2. Relationship to Literature: Does the paper demonstrate an adequate understanding of the relevant literature in the field and cite an appropriate range of literature sources? Is any significant work ignored?

The paper demonstrates a comprehensive understanding of the existing literature and makes good use of relevant sources.

Thank you. Clearly the context of families, food and consumer socialization are vast topics and areas which have been extensively studied for decades. We are enthused by your comments that we have demonstrated a comprehensive coverage of such issues, albeit within the confines of a tight word count.

3. Methodology: Is the paper's argument built on an appropriate base of theory, concepts or other ideas? Has the research or equivalent intellectual work on which the paper is based been well designed? Are the methods employed appropriate?

The methodological approach was appropriate and clearly explained.

Thank you. We wanted to do our best to capture the food practices of a range of families. Conducting research with families is time consuming and complex, although we thoroughly enjoyed our research encounters. Thanks again for agreeing that the method was appropriate and clearly explained.

4. Results: Are results presented clearly and analysed appropriately? Do the conclusions adequately tie together the other elements of the paper?

The results were clearly presented and analysed appropriately. However, I would like to know if there were any gender differences discernible within the emerging findings. This is both in terms of emotional reflexivity regarding one's own childhood food and their current practices (e.g. whether they employ a revisionist/ improver stance etc).

Thank you for highlighting that our results are presented clearly and appropriately. It was incredibly problematic to cover key issues in adequate depth and detail, as there is a lot to be addressed in the current manuscript. We feel that you raise an important issue though in 
relation to your comment about gender. Clearly the main focus of our manuscript was in capturing the general food socialization practices enacted by the primary food preparer in a family. As such, issues which specifically relate to gender fall somewhat outside the scope of our current work. Indeed, similar work that has represented gender issues as central focus to their studies (see, for example, Del Bucchia and Penaloza, 2016; Coskuner-Balli and Thompson, 2013) have used entire journal articles to adequately explore such differences between parents/parenting.

However, in order to respond to this issue - which we, too, have grappled with - we recognise that others have uncovered gender issues within family/food research, and we return to this issue within the directions for future research section. Coskuner-Balli and Thompson (2013) found that fathers delegate meal preparation to the marketplace, and Del Bucchia and Penaloza (2016) - now cited in our revised work - find that fathers do not express as negative feelings when a child refuses to eat - with fathers seen as less vulnerable to the discourse of good parenting than mothers. In our study, however, and again we need to recognise that our participants self-identified as being the main/primary food preparer for their family, the fathers didn't delegate meal preparation to the marketplace (contrasting with Coskuner-Balli and Thompson's work) and also reflected on intensive parenting ideology (in contrast to Del Bucchia and Penaloza's study). But again, this could be explained by the notion that these were highly active fathers within their families, who were responsible for the meals that their children ate. We comment on this - and call for further research in this area - in our revised manuscript/directions for future research section.

Thank you for highlighting this to us, and we hope we offer the reader some extra clarity in this regard. Your comments will inform our future research in this field.

5. Practicality and/or Research implications: Does the paper identify clearly any implications for practice and/or further research? Are these implications consistent with the findings and conclusions of the paper?

The paper identified practical implications for healthy eating campaigns and marketing communications. These are in line with the conclusions of the paper although they did appear a little simplistic. I wonder whether the research drawn upon in the paper also has the possibility to shed light on the complex way that campaigns might be received, taken on board or disregarded by individuals within a social and familial/ relationship context. It could be argued that although distancing oneself from parents' practices in the past may be realistic, alongside those where there is spousal conflict (see Chowbey 2017), however making healthier food choices than spouses and co-parents might be harder to achieve.

Thank you for your comment. You rightly pointed us in the direction of spousal conflict and the work of Chowbey (2017); now reflected in this section of our manuscript. We have now added the potential conflict between parents and co-parents into our discussion section and revised the section on how such notions could contribute to the practical implications of our paper, following your guidance. Thank you again for pointing this out. 
6. Quality of Communication: Does the paper clearly express its case, measured against the technical language of the fields and the expected knowledge of the journal's readership? Has attention been paid to the clarity of expression and readability, such as sentence structure, jargon use, acronyms, etc.

The paper is clearly expressed and readible. I was impressed by its level of presentation.

Thank you for your compliment!

However, I would suggest changing the title of the paper as I don't think the article answers 'How do parents teach their children about food?' It is more about how adults utilise/ avoid/ modify the family food memories from their childhood within their current practices.

This was an interesting paper to read and it has the potential to extend current understandings of how food work interacts with participants own childhood memories and emotions. The paper puts forward some practical implications but it would be useful to show more nuance in relation to how these may be interpreted in practice.

Following your above suggestion, we have amended coverage of the practical value of our work.

I would suggest changing the title of the paper as the article is not so much about 'How do parents teach their children about food?' as how adults reflect on the food in their own childhoods and continue or disregard certain approaches.

Thank you for highlighting this to us. With reflection, we agree. We have now revised our title to "Learning from the past? An exploratory study of familial food socialization processes using the lens of emotional reflexivity". The revised title takes in to consideration your point that the paper is actually about how adults reflect on the food in their own childhood "learning from the past" - and how this is continued/discontinued in their own parental style. Thank you for making this pertinent suggestion, and for all of your helpful and insightful comments (we are much obliged). 